\title{
Prevalence and associated factors of overweight/ obesity among children and adolescents in Ethiopia: a systematic review and meta-analysis
}

\author{
Alemu Gebrie $^{1 *}$, Animut Alebel ${ }^{2}$, Abriham Zegeye $^{1}$, Bekele Tesfaye $^{2}$ and Aster Ferede ${ }^{3}$
}

\begin{abstract}
Background: Overweight and obesity can be defined as excessive and abnormal fat depositions in our body. They have become one of the emerging and serious public health concerns of the twenty-first century in low income countries like Ethiopia. Hence, the aim of this study was to determine the pooled prevalence and review associated risk factors of overweight/obesity among children and adolescents in Ethiopia.

Method: The articles were identified through explicit and reproducible electronic search of reputable databases (PubMed, Google scholar, Science Direct, EMBASE, Cochrane library), and the hand search of reference lists of previous prevalence studies to retrieve more related articles. The 18 studies were selected based on a comprehensive list of inclusion and exclusion criteria. Data were extracted using a standardized and pre-tested data extraction checklist, and the analysis was done using STATA 14 statistical software. To assess heterogeneity, the Cochrane $Q$ test statistic and $P$ tests were used. Since the included studies exhibited considerable heterogeneity, a random effect model was used to estimate the pooled prevalence of overweight/obesity. Moreover, the risk factors of overweight/obesity were reviewed.
\end{abstract}

Results: The combined pooled prevalence of overweight and obesity among children and adolescents in Ethiopia was $11.30 \%$ (95\% Cl: 8.71, 13.88\%). Also, the separate pooled prevalence of overweight and obesity were 8.92 and $2.39 \%$, respectively. Subgroup analysis revealed that the highest overweight/obesity prevalence among children and adolescents was observed in Addis Ababa, 11.94 (95\% Cl: 9.39, 14.50). Female gender of the children: 3.23 (95\% Cl 2.03,5.13), high family socioeconomic status: 3.16 (95\% Cl 1.87,5.34), learning in private school: 3.22 (95\% Cl 2.36,4.40), physical inactivity: 3.36 (95\% Cl 1.68,6.72), sweet nutriments preference: 2.78 (95\% Cl 1.97,3.93) and less use of fruits/vegetables: $1.39(95 \% \mathrm{Cl} 1.10,1.75)$ have shown a positive association with the development of overweight/obesity among children and adolescents.

Conclusion: The pooled prevalence of overweight/obesity among children and adolescents in Ethiopia is substantially high, and has become an emerging nutrition linked problem. Female gender, high family socioeconomic status, learning in private school, physical inactivity, sweet nutriments preference and less use of fruits/vegetables were found to be significantly associated with overweight/obesity.

Keywords: Overweight, Obesity, Associated factors, Children, Adolescents, Ethiopia

\footnotetext{
* Correspondence: alemugebrie2@gmail.com

'Department of Biomedical Science, School of Medicine, Debre Markos

University, P.O. Box 269, Debre Markos, Ethiopia

Full list of author information is available at the end of the article
}

(c) The Author(s). 2018 Open Access This article is distributed under the terms of the Creative Commons Attribution 4.0 International License (http://creativecommons.org/licenses/by/4.0/), which permits unrestricted use, distribution, and reproduction in any medium, provided you give appropriate credit to the original author(s) and the source, provide a link to the Creative Commons license, and indicate if changes were made. The Creative Commons Public Domain Dedication waiver (http://creativecommons.org/publicdomain/zero/1.0/) applies to the data made available in this article, unless otherwise stated. 


\section{Background}

Overweight and obesity can be defined as excessive and abnormal fat depositions in our body. They are major risk factors for several diet-linked non-communicable diseases like dyslipidemia, cardiovascular diseases (CVD), and type II diabetes mellitus [1-4]. Worldwide, overweight/ obesity is becoming one of the most challenging current health concerns with the worrisome rise in children and adolescents. Contemporary evidence revealed that the worldwide prevalence of overweight / obesity among children and adolescents were $13.5 \%$ [5]. In Africa, under-nutrition is the major nutritional problem affecting both children and adolescents. However, overweight/obesity is noticeably high with a prevalence of $8.5 \%$ in 2010 and predicted to be $12.7 \%$ by 2020. This situation pinpoints a double burden of malnutrition, and epidemiological as well as nutrition transition by virtue of several socioeconomic and demographic changes [5-7].

Studies showed that many factors can potentially be associated with overweight/obesity in children and adolescents $[8,9]$. Those factors that are of maternal origin were socioeconomic status, education level, marital status, and smoking status during pregnancy. Gender of the children and adolescents, weight at birth, their birth rank, and residence were also the factors associated with overweight /obesity among them $[10,11]$. Children and adolescents in developing countries are prone to sugar, high fat salts, energy rich foods and micronutrient-poor foods that are less costly and lower in nutrient quality. These dietary habits in combination with other factors result in substantial upsurge of overweight/obesity [12].

School based health education and promotion tactics such as enhancing physical activity among the children and adolescents, vegetables and fruits intake have been helpful to minimize overweight/obesity [13]. To solve this emerging health problem, Ethiopia incorporated the concern of overweight/obesity into the national nutrition program and launched an initiative to promote physical activity in the population [6]. Nevertheless, the efforts do not target children and adolescents in particular.

In different regions of Ethiopia, several independent and fragmented studies [14-30] were conducted in children and adolescents to assess the prevalence and associated factors of overweight / obesity, but there was a great variation and inconsistency of the findings among the studies. Hence, the aim of this review was to determine the pooled prevalence and associated factors of overweight/obesity in children and adolescents in Ethiopia. The results of the present study will elevate the need for policy makers, program planners, guardians or parents, clinicians as well as concerned stakeholders to give more emphasis for childhood overweight / obesity in the country. The review question is: What is the best available evidence on the prevalence and associated factors of overweight and/or obesity among children and adolescents in Ethiopia?

\section{Methods}

\section{Literature search approach and study design}

For its rigor, this study was guided by Preferred Reporting Items for Systematic Reviews and Meta-Analyses (PRISMA) [31]. The articles for this study were identified through comprehensive and reproducible electronic search of reputable databases (PubMed, Google scholar, Science Direct, EMBASE, Cochrane library), and the hand search of reference lists of previous prevalence studies to retrieve more related articles. The researchers also used the "related articles" option of PubMed and checked the reference lists of the original and review articles to detect more relevant publications. The search was independently performed by the two authors (AG, AA) using the following key terms: (a) population (preschool, children, schoolchildren, school aged, childhood, schooler, preadolescent, adolescent); (b) outcome (body composition, overweight, over nutrition, obesity, body constitution, weight status, body mass index, anthropometry; (c) study design (cross-sectional, prevalence, epidemiology, observational, pattern); and (d) location (Ethiopia and regions of Ethiopia) both in separation and in combination using the Boolean operator like "OR", "AND" or "NOT". Before searching the databases, the appropriateness of searching words was verified for retrieving the relevant articles. The literature search was limited to English language, and human study category. The literature records were managed using the EndNote X7 reference manager. The articles were searched from September, 2017 to November, 2017 and all the articles accessed until November, 2017 were included in this systematic review and meta-analysis.

\section{Selection of studies Inclusion criteria}

The two investigators independently and reproducibly assessed the contents of each of the identified studies (AG and AA). Those articles which met the following criteria were included in the study.

Population: Articles conducted among children and adolescents (age $<20$ years) were considered.

Study area: Only articles conducted in Ethiopia were considered.

Study design: Original studies that reported the prevalence and associated risk factors of overweight and/ or obesity, measured objectively by trained personnel, among children in Ethiopia were considered.

Language: Only articles published in English language were considered. 
Publication condition: Studies that fulfilled the eligibility criteria were included regardless of their publication status (published, unpublished and grey literature, etc.)

\section{Exclusion criteria}

After screening the abstracts and the full texts of the articles, the three researchers (AG, AA and AF) carried out the data extraction independently and blindly. Articles with methodological problems were excluded by the three independent researchers after reading the full text as well as abstracts. The articles the full texts of which we were not able to fully access or failed to contact their primary authors were excluded from this review because of incomplete data.

\section{Data abstraction and critical appraisal of the studies}

The two researchers independently extracted all the necessary data using a standardized and pre-tested data extraction checklist. The necessary data extracted from the articles included: first author of the study, region in Ethiopia where the study was carried out, the particular area where the study was conducted, study design, publication year of the study, sample size, response rate, and prevalence of overweight/obesity. Any sort of discrepancies between the researchers on the data extracted were solved through discussion and consensus as well as through involvement of the third reviewer (AZ).

The reviewers employed the Newcastle-Ottawa quality assessment tool Scale adapted for cross-sectional studies so as to appraise the qualities of the studies [32]. The tool is composed of three important indicators. The first part is graded from five points (stars) and evaluates the methodological qualities of the studies. The second part has three stars and assesses the comparability of the studies. The last section of the tool is graded from two points and measures the quality of the original studies in terms of their statistical analyses. By using the tool as a guiding protocol, the two authors (AG and AA) appraised the qualities of the primary studies independently.

The qualities of the studies were assessed by using the following indicators; those with medium (fulfilling $50 \%$ of quality assessment criteria) or high quality ( $\geq 6$ out of 10 scales) were considered for inclusion in the meta-analysis. Taking the mean score of the two reviewers, differences of their assessment results were determined.

\section{Operationalization of the outcomes of the review}

Firstly, the percentage of overweight/obesity among children and adolescents was the foremost outcome of the meta-analysis. The second outcome of the study was to examine the factors that are associated with overweight/ obesity among the study subjects. The prevalence was obtained by dividing the number of children and/or adolescents who are either overweight or obese to the total number of children and/or adolescents who have been included in the study (sample size) then multiplied by 100. The association between overweight/obesity and the factors were quantified by odds ratio. The odds ratio was calculated from the two by two table reports of the primary studies.

\section{Data analysis/synthesis of results}

After the relevant data had been extracted from the studies by using Microsoft excel 2016 format, the authors then analyzed the results by using STATA version 14.0 (STATA Corporation, College Station Texas) software. The original studies were summarized and presented by using a table and the forest plot. The authors computed the standard error of prevalence of overweight/obesity for each original study by using binomial distribution formula. We explored the potential heterogeneity among the reported prevalence of the studies using $\mathrm{I}^{2}$ test and Cochrane Q statistics [33]. Since the test statistics revealed that there was a considerable heterogeneity [34] among the studies $\left(\mathrm{I}^{2}=96.9 \%, p=0.000\right)$, a random effects model was used to estimate the Der Simonian and Laird's pooled effect. We also undertook univariate meta-regression analysis taking publication year of the studies and the sample size to detect the potential source(s) of variation but both of them were found to be statistically insignificant, $(p=0.65$ and $p=$ 0.45 respectively). Possible publication bias was also objectively examined using Egger's weighted correlation and Begg's regression intercept tests at 5\% significant level respectively $[35,36]$. The test results showed there is a significant publication bias $(p=0.000)$, and therefore the final effect size was determined by applying Duval and Tweedie's Trim and Fill analysis in the Random-effects model. In addition, to minimalize the random variations between the point estimates of the original studies, subgroup analysis was carried out based on region of studies and publication year.

\section{Results}

\section{Identification of eligible studies}

From the outset, we searched a total of 602 records by the electronic search through a search engine of MEDLINE/PubMed, Google scholar, science direct, EMBASE, Cochrane Library and reference lists of previous related studies to retrieve more related articles. Since there were duplications in the records, 195 of them were removed from the inclusion. After assessing the abstracts and titles, the remaining 407 retrievals, 371 records were excluded since they were not relevant for this meta-analysis in terms of outcome the study is interested. Then, 36 full text studies were considered and assessed for eligibility based on the pre-set eligibility criteria. Finally, 18 studies were considered to 
be eligible and included in this systematic review and meta-analysis (Fig. 1).

From a total of 36 full text studies accessed, we removed twelve of them because they were review articles, and /or conducted in other nations which are not the location of interest of the study like: USA [37, 38], Russia [39], Japan [40], Yemen [41], Nigeria [42-45], South Africa [46], Egypt [47] and Morocco [48]. Moreover, six full text studies [49-54] that have been carried out from different parts of Ethiopia were excluded because their outcome measures were not prevalence of overweight/obesity in children and they were conducted in the adult population which is not the population of interest of the this study.

\section{Description of original studies}

Table 1 summarizes the descriptive characteristics of the 18 studies included in this systematic review and meta-analysis. All the studies were cross sectional by design, and conducted in different parts of Ethiopia with a sample size ranging from 174 in Adama, Oromia region [26] to 9880 in a national survey [55]. The included studies have been conducted from 2010 to 2017. In the current systematic review and meta-analysis, a total of 19,031 children and adolescents were included to estimate the pooled prevalence of overweight/obesity.

The 18 studies have been conducted in the six regions of Ethiopia: about one third (six) of the included studies were carried out in Addis Ababa: Addis Ababa [19, 2123, 29, 30], Dire dawa [14], Amhara [17, 18, 21, 24], Harari [28], Oromia [15, 25, 26], Southern Nations, Nationalities and peoples' region (SNNPR) $[20,27]$ and one nationwide survey study [55]. Whereas the highest prevalence of overweight/obesity (20.54\%) was reported in Dire dawa [14], the nationwide survey study [55] reported the lowest prevalence $(3 \%)$ of the problem. Furthermore, the original studies included in this meta-analysis and reporting response rate had a response rate that ranges from 91 to 100\% showing that all the studies had good response rate.

Concerning the quality of the articles: only one [29] of the 18 studies was unpublished article and the studies included in the meta-analysis were identified by exhaustive search from reputable journals like PubMed. Blinded

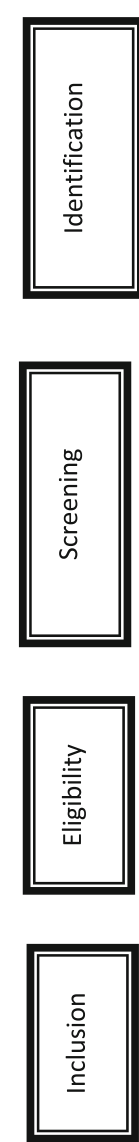

Articles identified through electronic database searching: PubMed (366), Google scholar (123), science direct (90) $(n=579)$

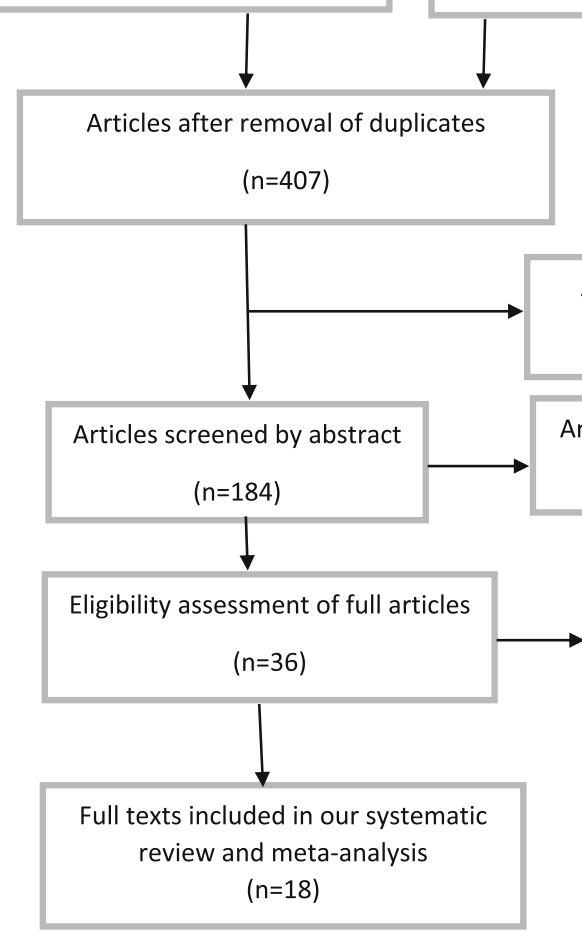

$(n=23)$

Articles excluded by title

$(n=223)$

Additional articles identified through other sources

Articles excluded by abstract

$(n=148)$

Reasonable exclusion of full articles $(n=18)$

$\checkmark$ Review articles

$\checkmark$ Outcome of interest not reported

$\checkmark$ Conducted in other countries

Fig. 1 Flow chart diagram describing selection of studies for the systematic review and meta-analysis of prevalence and associated factors of overweight/obesity among children and adolescents in Ethiopia, 2018 (identified, screened, eligible and included studies). Articles may have been excluded for more than one reason 
Table 1 Characteristics of 18 studies reporting the prevalence of overweight/obesity among children and adolescents in Ethiopia included in the current systematic review and meta-analysis, 2018

\begin{tabular}{|c|c|c|c|c|c|c|c|}
\hline Region & Area & Author & Publication year & Sample size & Response rate (\%) & $\begin{array}{l}\text { Quality score } \\
\text { (10 pts) }\end{array}$ & $\begin{array}{l}\text { Prevalence } \\
(95 \% \mathrm{Cl})\end{array}$ \\
\hline \multirow[t]{6}{*}{ Addis Ababa } & Addis Ababa & Gebremichael et al. [22] & 2017 & 463 & 96.9 & 6 & $12.74(9.71,15.78)$ \\
\hline & Bole subcity & Askal et al. [19] & 2015 & 828 & 97.9 & 7 & $9.78(7.76,11.81)$ \\
\hline & Addis Ababa & Dessalegn and Robel [29] & 2016 & 390 & 96.3 & 6 & $18.21(14.38,22.03)$ \\
\hline & Addis Ababa & Mulugeta et al. [30] & 2016 & 446 & 97.8 & 6 & $15.25(11.91,18.58)$ \\
\hline & Arada subcity & Alemu et al. [23] & 2014 & 800 & 100 & 7 & $9.38(7.36,11.39)$ \\
\hline & Addis Ababa & Yoseph et al. [16] & 2014 & 1024 & 100 & 6 & $8.50(6.79,10.20)$ \\
\hline \multirow[t]{4}{*}{ Amhara } & Bahirdar & Tadesse et al. [21] & 2017 & 462 & 97 & 8 & $6.93(4.61,9.24)$ \\
\hline & Gondar & Sorrie et al. [18] & 2017 & 500 & 99.2 & 8 & $13.80(10.78,16.82)$ \\
\hline & Gondar & Gebremedhin et al. [17] & 2013 & 791 & 98.9 & 7 & $5.94(4.29,7.59)$ \\
\hline & Bahirdar & Zelalem et al. [24] & 2015 & 431 & 95.6 & 8 & $16.71(13.18,20.23)$ \\
\hline Dire dawa & Dire dawa & Desalew et al. [14] & 2017 & 448 & 98.2 & 7 & $20.54(16.80,24.28)$ \\
\hline Ethiopia & Ethiopia & EDHS [55] & 2011 & 9880 & $N R$ & 7 & $3.00(2.66,3.33)$ \\
\hline Harari & Babile & Kedir Teji et al. [28] & 2016 & 547 & 91 & 6 & $5.85(3.88,7.82)$ \\
\hline \multirow[t]{3}{*}{ Oromia } & Ambo & Mesert Yetubie et al. [25] & 2010 & 425 & $N R$ & 7 & $8.71(6.03,11.39)$ \\
\hline & Jimma & Dessalegn et al. [15] & 2017 & 510 & 93.4 & 8 & $13.33(10.38,16.28)$ \\
\hline & Adama & Wakayo et al. [26] & 2016 & 174 & 98 & 7 & $10.92(6.29,15.55)$ \\
\hline \multirow[t]{2}{*}{ SNNP } & Hawasa & Woldie and Belachew [20] & 2014 & 358 & 100 & 7 & $10.61(7.42,13.81)$ \\
\hline & Hawasa & Teshome et al. [27] & 2013 & 554 & 97 & 5 & $15.70(12.67,18.73)$ \\
\hline
\end{tabular}

reviewers re-evaluated all the studies before analysis and the articles were found fit for their quality (quality score ranged from 5 to 8 out of 10 points).

\section{Meta-analysis and meta-regression}

As it is depicted in the forest plot of 18 included studies below (Fig. 2a), the combined pooled prevalence of overweight and obesity among children and adolescents in Ethiopia was $11.30 \%$ (95\% CI: 8.71, 13.88\%). Also, from the 16 studies, the separate pooled prevalence of overweight and obesity were 8.92 and $2.39 \%$, respectively (Fig. 2b and c). Considerable heterogeneity [34] was observed among the 18 studies and detected by $\mathrm{I}^{2}$ statistic $\left(\mathrm{I}^{2}=96.9, p\right.$ value $\left.<0.000\right)$. As a result, the DerSimonian and Laird random-effects method, which gives more conservative estimate, was used to estimate the overall pooled prevalence of overweight and obesity among children and adolescents. To determine the likely sources for the variation, we checked the potential factors associated with the prevalence variation, publication year and sample size by using univariate meta-regression models but both of them were found to be statistically insignificant for the variation (Table 2). Egger's and Begg's tests showed that there is a statistically significant publication bias, $(p=0.000)$ and $(p=0.002)$ respectively. Hence, we performed Trim and Fill analysis so as to adjust the final pooled prevalence of overweight/obesity among the subjects.

\section{Subgroup analysis}

We have also performed subgroup analysis based on the region where the studies were carried out and year of publication of the studies to assess possible causes of considerable heterogeneity. As per the result, the highest prevalence of overweight/obesity among children and adolescents was observed in Addis Ababa, where most of the studies have been conducted, with a prevalence of 11.94 (95\% CI: 9.39, 14.50) followed by regions classified (in this study) as others, $10.97 \%$ (95\% CI: $5.09,16.85$ ) and Oromia region $10.94 \%$ (95\% CI: $7.86,14.02)$ (Table 3). Regarding year of publication, the prevalence of childhood overweight/obesity was significantly higher in studies which have been published since 2014, 12.95\% (95\% CI: 10.17, 15.73) compared to those articles published before 2014, 8.70\% (95\% CI: 5.40, 11.99) (Table 3).

\section{Associated factors of overweight/obesity among children and adolescents}

We have comprehensively reviewed and meta-analyzed the associated risk factors of overweight/obesity among children and adolescents by using thirteen relevant studies $[14-20,23,24,26,27,29,30]$ from the eligible articles included in this study. Sex of the children, family income, family educational status, type of school the children attend, physical activity status, habit of using sweet nutriments, use of fruits and vegetables were found to be worth reviewing and meta-analyzable. They 
a Study ID

$\mathrm{ES}(95 \% \mathrm{Cl})$

Tadesse et al (2017) Desalew et al (2017) Sorrie et al (2017)

Gebremichael et al (2017)

Woldie and Belachew (2014)

Askal et al (2015)

Dessalegn and Robel (2016)

Mulugeta et al (2016)

Gebremedhin et al (2013)

Alemu et al (2014)

Zelalem et al (2015)

Mesert Yetubie et al (2010)

Yoseph et al (2014)

Dessalegn et al (2017)

EDHS (2011)

Wakayo et al (2016)

Kedir Teji et al (2016)

Teshome et al (2013)

Overall (I-squared $=96.9 \%, p=0.000$ )

NOTE: Weights are from random effects analysis

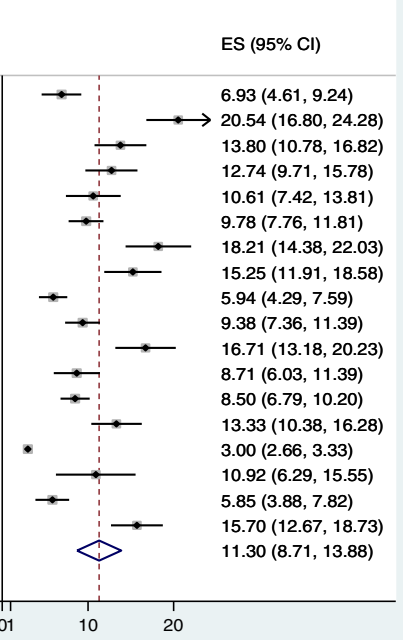

b study

ID

ES (95\% Cl)

$4.11(2.30,5.92)$

Tadesse et al (2017)

Desalew et al (2017)

Sorrie et al (2017)

Gebremichael et al (2017)

Woldie and Belachew (2014)

Askal et al (2015)

Dessalegn and Robel (2016)

Mulugeta et al (2016)

Gebremedhin et al (2013)

Alemu et al (2014)

Zelalem et al (2015)

Dessalegn et al (2017)

EDHS (2011)

Wakayo et al (2016)

Kedir Teji et al (2016)

Teshome et al (2013)

Overall (I-squared $=96.8 \%, p=0.000$ )

NOTE: Weights are from random effects analysis

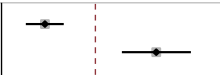

$14.73(11.45,18.01)$

$9.60(7.02,12.18)$

\begin{tabular}{ll}
$9.94(7.21,12.66)$ \\
\hdashline$\quad 7.26(4.57,9.95)$
\end{tabular}

$\rightarrow+26(4.57,9.95)$
$\rightarrow$$\quad 7.97(6.13,9.82)$

$\longrightarrow \quad 14.36(10.88,17.84)$

$\begin{array}{llll}0 & 0 & 10 & 20\end{array}$

C

Study

ID

ES $(95 \% \mathrm{Cl})$

Tadesse et al (2017)

Desalew et al (2017)

Sorrie et al (2017)

Gebremichael et al (2017)

Woldie and Belachew (2014)

Askal et al (2015)

Dessalegn and Robel (2016)

Mulugeta et al (2016)

Gebremedhin et al (2013)

Alemu et al (2014)

Zelalem et al (2015)

Dessalegn et al (2017)

EDHS (2011)

Wakayo et al (2016)

Kedir Teji et al (2016)

Teshome et al (2013)

Overall (I-squared $=82.9 \%, p=0.000$ )

$10.31(7.49,13.14)$

$5.44(3.86,7.02)$

$8.63(6.68,10.57)$

$12.30(9.20,15.40)$

$11.76(8.97,14.56)$

$1.70(1.45,1.96)$

$8.62(4.45,12.79)$

$4.75(2.97,6.54)$

$13.00(10.20,15.80)$

$8.92(6.45,11.40)$

NOTE: Weights are from random effects analysis

$2.81(1.31,4.32)$

$5.80(3.64,7.97)$

$4.20(2.44,5.96)$

$2.81(1.30,4.31)$

$3.35(1.49,5.22)$

$1.81(0.90,2.72)$

$3.85(1.94,5.75)$

$4.93(2.92,6.94)$

$0.51(0.01,1.00)$

$0.75(0.15,1.35)$

$4.41(2.47,6.35)$

$1.57(0.49,2.65)$

$1.30(1.07,1.52)$

$2.30(0.07,4.53)$

$1.10(0.22,1.97)$

$2.71(1.36,4.06)$

$2.39(1.81,2.97)$

Fig. 2 Forest plot of the pooled prevalence of overweight and obesity in children and adolescents, 2018 (a: The combined pooled prevalence of overweight/obesity; $\mathbf{b}$ : The pooled prevalence of overweight; $\mathbf{c}$ : The pooled prevalence of obesity) 
Table 2 Related factors with the heterogeneity of overweight/ obesity prevalence among children and adolescents in Ethiopia in the meta-analysis (univariate meta-regression)

\begin{tabular}{lll}
\hline Variables & Coefficient & $P$-value \\
\hline Year of publication studies & 0.2866022 & 0.817 \\
Sample sizes of the studies & -0.0005473 & 0.411 \\
\hline
\end{tabular}

were associated with overweight/obesity among children and adolescents in Ethiopia (Fig. 3). We have also performed sensitivity analysis for each of the factors but none of the studies revealed significant difference.

The pooled effect size of six studies showed that female children and adolescents were 3.23 times more likely to be overweight/obese than their male counterparts, odds ratio 3.23 (95\% CI 2.03,5.13) (Fig. 3a). The pooled result of ten studies also revealed that children and adolescents from high income families were 3.16 times more likely to be overweight/obese as compared to those children with middle and low-income families, odds ratio 3.16 (95\% CI 1.87,5.34) (Fig. 3b). Those children and adolescents whose families are not illiterate (educated) were 1.57 times more likely to have overweight or obesity compared to those whose families are illiterate, odds ratio 1.57 (95\% CI 0.93,2.64) (Fig. 3c).

We have also found that children and adolescents attending at private schools were 3.22 times more likely to develop overweight/obesity as compared to those attending at governmental schools, odds ratio 3.22 (95\% CI 2.36,4.40) (Fig. 3d). Physically inactive children and adolescents were also 3.36 times more to be overweight/ obese than those children who were physically active, odds ratio 3.36 (95\% CI 1.68,6.72) (Fig. 3e). In addition, children and adolescents who had the habit of using sweet food stuffs were 2.78 times more likely to suffer from the emerging nutritional problem of overweight and obesity as compared to those children who have seldom used sweet food items, odds ratio 2.78 (95\% CI 1.97,3.93) (Fig. 3f). Moreover, the results of three studies showed that infrequent consumption of fruits and vegetables was a risk factor for the development of overweight/obesity among children, odds ratio 1.39 (95\% CI 1.10,1.75) (Fig. 3g).

\section{Discussion}

Overweight/obesity, an emerging nutritional problem in developing countries, increases the burden of nutrition related diseases and have far-reaching consequences on economic growth of countries [4-6, 12]. Evidences have revealed that nutrition-linked non-communicable diseases are significantly in upsurge over time. In contrary to previous concerns that mainly focused on the issue of under nutrition, overweight/obesity is now emerging as a nutrition related public health burden. The problem is debilitating and a double burden in low income communities in different parts of Africa most importantly in Ethiopia. Therefore, the result of the present study is of paramount importance in pinpointing the emerging problems of nutrition-linked concerns particularly among children and adolescents in the country.

A systematic review and meta-analysis has not yet been carried out to estimate the pooled prevalence of overweight/obesity, and review its associated factors among children and adolescents in Ethiopia. However, about 18 cross sectional studies, which are relevant for this research question, have been conducted in different parts of Ethiopia. Hence, the aim of this study was to estimate the pooled prevalence of overweight/obesity as well as to identify and review the risk factors that are associated with it among the study subjects. Using those relevant studies, the result of this meta-analysis showed that the combined overall prevalence of overweight and obesity, as per WHO 2007 definition, was 11.30\% (95\% CI: $8.71,13.88 \%$ ) among children and adolescents in the country. This prevalence is substantially high even comparable with the results reported for some developed countries $(8.7 \%)$ a couple of years ago, and higher than the global prevalence $(7 \%)[56,57]$. Despite methodological differences, nutritional patterns and the availability of recreational facilities may be attributed for the variation in the results, the findings of this study clearly indicate that there is a nutrition transition, and overweight/obesity is becoming a growing problem and a double burden in the country.

Also, the subgroup analysis of this meta-analysis revealed that the prevalence of childhood overweight/obesity varies across the regions of Ethiopia. The prevalence

Table 3 Results from subgroup analysis of the prevalence of overweight/obesity among children and adolescents in Ethiopia, 2018 $(n=18)$

\begin{tabular}{llll}
\hline Variables & Characteristics & Number of studies & Prevalence with 95\% \\
\hline Region & Addis Ababa & 6 & $11.94(9.39,14.50)$ \\
& Amhara & 4 & $10.66(5.92,15.41)$ \\
& Oromia & 3 & $10.94(7.86,14.02)$ \\
Year of publication & Others & 5 & $10.97(5.09,16.85)$ \\
& $\leq 2014$ & 7 & $8.70(5.40,11.99)$ \\
& $>2014$ & 11 & $12.95(10.17,15.73)$ \\
\hline
\end{tabular}




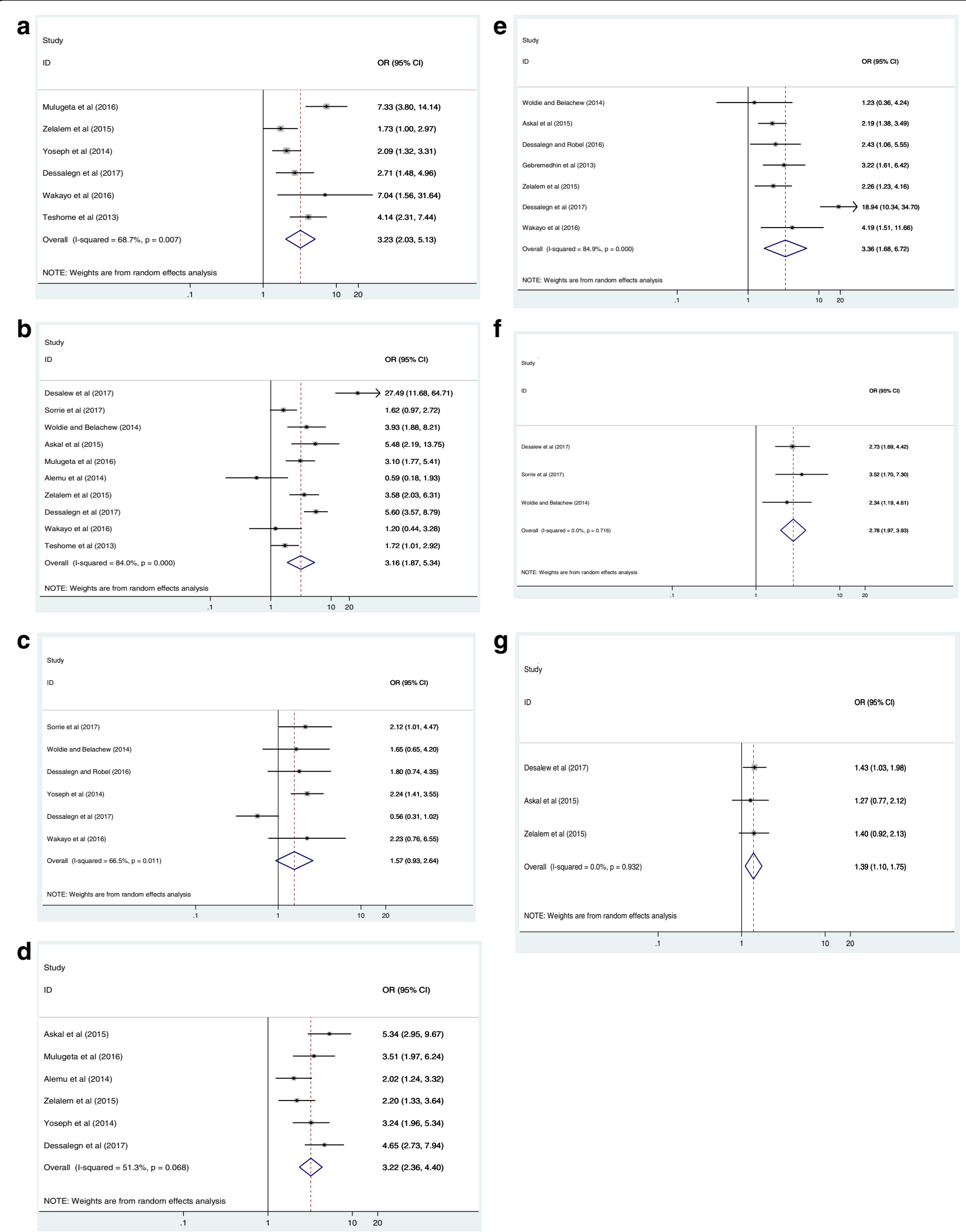

Fig. 3 Forest plot showing the pooled odds ratio of the associations between overweight/obesity and its purported associated risk factors among children and adolescents in Ethiopia (a: Sex, b: Family income, c: Family education, d: School type of children, e: Physical activity, f: Use of sweet food, $\mathbf{g}$ : use of fruits and vegetables) 
was highest in children and adolescents of Addis Ababa as compared to other regions of the country. This could be due to better access to high calorie diets because of better socioeconomic status of the population in the capital compared to other regions of the country [4]. The prevalence of overweight/obesity was also significantly higher in those studies published since 2014 as compared to studies published before 2014. This shows that childhood overweight/obesity is increasing alarmingly in the country [57].

We reviewed and meta-analyzed the risk factors related with overweight/obesity among children and adolescents that have been addressed by the relevant studies. The risk of developing childhood overweight/ obesity among females was higher than males in this review. Though they are not reviews, the result was congruent with studies conducted in African countries that female subjects were more likely to be at risk of having overweight/obesity compared to the male ones [58, 59]. But the result is in contrary to studies conducted from other countries [60-62] in which overweight/obesity was more prevalent in males than females. However, the prevalence in most developing countries is more in females which is true for this meta-analysis too. This may be explained that there is a biological difference in energy need for males and females in relation to rate of growth and timing of sexual maturation [63]. Males are also more physically active than females particularly during childhood [64]. In addition, in developing countries such as Ethiopia, girls usually stay at home for long period and there is a cultural influence not to move much from place to place than boys leading to physical inactivity and ultimately the development of overweight and obesity.

Children and adolescents from families with high monthly income were more likely to be overweight/ obese as compared to those from families with low and moderate income. This is in line with a study done in Saudi Arabia [65], but in contrary to studies conducted in Germany and Korea [66, 67] where lower income was found to significantly increase the risk of being overweight/obese in the study subjects. This could be due to the reason that adolescents from socioeconomic status families have access for fat rich foods and follow sedentary life style. On the other hand, patterns of high expenditure of energy among the poor families and cultural attitude towards a larger body size tendency could also contribute to the positive relations observed. In lower-income countries like Ethiopia childhood overweight/obesity has been considered as a sign of better social status, and healthiness [68].

In contrast to cross sectional studies conducted in developed countries like Brazil and Iran [69, 70], the educational level of families was positively associated with overweight/obesity in the subjects but not statistically significant. Those children and adolescents whose mothers had primary educational level and above were more likely to be overweight/obese as compared to mothers with no education. This shows that educated mothers in developing countries fail to make healthy choices regarding food stuffs like the incorporation of fruits and vegetables in the diet.

There was a remarkable difference in the prevalence of overweight/obesity between government and private schools where children attended. The odds of having overweight/obesity was higher among children attending at private schools than those at governmental schools. This is in trajectory with studies conducted in India [71], Yemen [72], Saudi Arabia [73], Kenya [74] and Burkina Faso [66]. Often, children attending private schools are from families of higher socioeconomic status. Therefore, they are exposed to unhealthy nutritional patterns such as highly-processed and fast foods, more animal products as well motorized lifestyle compared to those children attending government schools.

In addition, adolescents not engaged in physical activities were more likely to be overweight and obese compared to those who were doing physical activities. The finding is concordant to other cross-sectional studies $[75,76]$. The possible explanation could be because doing physical exercise burns off body fat (negative energy balance) leads to less risk of overweight/obesity. Children who consumed sweetened foods were more likely to be overweight/obese compared to those who didn't consumed. This was congruent with WHO report of different studies done in Europe [77], Egypt [78], Kenya [79]. This could be reasoned out that sweet food products are calorie rich and have a greater acceptance by children and adolescents resulting in a positive energy balance to them. Moreover, the results of three studies showed that infrequent consumption of fruits and vegetables was a risk factor for the development of overweight/obesity among children and adolescents.

\section{Strengths and limitations of the study}

The strengths of this study were the use of multiple reputable databases to exhaustively and explicitly search eligible literatures as well as uniform and reproducible extraction of data using a preset and pretested checklist so as to minimize errors. This systematic review and meta-analysis also included studies from different regions of the country. However, the study may have some potential limitations for it is restricted to articles published in English language. In addition, by virtue of the cross-sectional nature of the studies reviewed, temporal relationship cannot be established between the factors and overweight/obesity. Despite the incorporation of studies from different parts of the country, the 
representativeness of the population is not so strong as it could have been. Therefore, one had better interpret the findings of this systematic review and meta-analysis in context of the inherent limitations of both the original studies and the present review.

\section{Conclusions}

This meta-analysis revealed that the prevalence of overweight/obesity among children and adolescents in Ethiopia is substantially high, and has become an emerging nutrition linked problem. Unless successful preventive measures are taken, the problem may continue on upsurge in the future. Female gender of the children, high family socioeconomic status, learning in private school, physical inactivity, sweet nutriments preference and less use of fruits/vegetables were found to be significantly associated with overweight/obesity among the study subjects. We have recommended that integrated nutrition education program has to be successfully implemented in schools as well as in communities with existing health extension programs. Healthcare providers and policymakers should also give more emphasis on the design and implementation of preventive policies to control the rising prevalence of childhood overweight/ obesity in Ethiopia.

\section{Abbreviations}

PRISMA: Preferred Reporting Items of Systematic Reviews and Meta-Analysis: SNNPE: Southern Nations, Nationalities and peoples of Ethiopia; USA: United States of America

\section{Funding}

We have not obtained any fund for this study.

\section{Availability of data and materials}

Data will be available upon request of the corresponding author.

\section{Authors' contributions}

AG: Conception of research protocol, study design, literature review, data extraction, data analysis, interpretation and drafting the manuscript. AA, AZ, AF and BT: Data extraction, analysis and reviewing the manuscript and quality assessment. All authors read and approved the manuscript.

\section{Ethics approval and consent to participate}

Not applicable.

\section{Competing interests}

The authors declare that they have no competing interests.

\section{Publisher's Note}

Springer Nature remains neutral with regard to jurisdictional claims in published maps and institutional affiliations.

\section{Author details}

${ }^{1}$ Department of Biomedical Science, School of Medicine, Debre Markos University, P.O. Box 269, Debre Markos, Ethiopia. ${ }^{2}$ Department of Nursing, College of Health Sciences, Debre Markos University, Debre Markos, Ethiopia. ${ }^{3}$ Department of Public Health, College of Health Sciences, Debre Markos University, Debre Markos, Ethiopia.
Received: 7 February 2018 Accepted: 22 May 2018

Published online: 09 July 2018

\section{References}

1. Organization WH: Global strategy on diet, physical activity and health. 2004 H ttp. wwwwho, Int/dietphysicalactivlty/en.

2. Van Der Sande MA, Ceesay SM, Milligan PJ, Nyan OA, Banya WA, Prentice A, McAdam KP, Walraven GE. Obesity and undernutrition and cardiovascular risk factors in rural and urban Gambian communities. Am J Public Health. 2001;91(10):1641-4.

3. WHo J, Organization WH: Diet, nutrition and the prevention of chronic diseases: report of a joint WH. 2003

4. WHO Diet, nutrition and the prevention of chronic diseases. World Health Organ Tech Rep Ser. 2003;916:i-viii-1-149.

5. Berman ML. From health care reform to public health reform. J Law Med Ethics. 2011;39(3):328-39.

6. Demissie T, Ali A, Mekonen Y, Haider J, Umeta M. Food Nutr Bull. 2010;31(2): 234-41.

7. Overseas-Development-Institute: Future diets: obesity rising to alarming levels around the world. 2014 . http://www.odi.org/future-diets. 2015 [cited 05 May 2015]

8. Roberts KC, Shields M, de Groh M, Aziz A, Gilbert J-A. Overweight and obesity in children and adolescents: results from the 2009 to 2011 Canadian health measures survey. Health Rep. 2012;23(3):37-41.

9. Vohra R, Bhardwaj P, Srivastava JP, Srivastava S, Vohra A. Overweight and obesity among school-going children of Lucknow city. J Family Community Med. 2011;18(2):59.

10. Toselli S, Zaccagni L, Celenza F, Albertini A, Gualdi-Russo E. Risk factors of overweight and obesity among preschool children with different ethnic background. Endocrine. 2015;49(3):717-25.

11. Rossen $L M$, Talih M. Social determinants of disparities in weight among US children and adolescents. Ann Epidemiol. 2014;24(10):705-13. e702

12. World Health Organization. Obesity and Overweight, Fact Sheet No 311. 2011.

13. Langford R, Bonell C, Jones H, Campbell R. Obesity prevention and the health promoting schools framework: essential components and barriers to success. Int J Behav Nutr Phys Act. 2015;12(1):15.

14. Desalew A, Mandesh A, Semahegn A. Childhood overweight, obesity and associated factors among primary school children in Dire Dawa, eastern Ethiopia; a cross-sectional study. BMC obesity. 2017:4(1):20.

15. Gali N, Tamiru D, Tamrat M. The emerging nutritional problems of school adolescents: overweight/obesity and associated factors in Jimma town, Ethiopia. J Pediatr Nurs. 2017;35:98-104.

16. Gebreyohannes Y, Shiferaw S, Demtsu B, Bugssa G. Nutritional status of adolescents in selected government and private secondary schools of Addis Ababa, Ethiopia. Adolescence. 2014;10:11.

17. Gebregergs G, Yesuf M, Beyen T. Overweight and obesity, and associated factors among high school students in Gondar town, north West Ethiopia. J Obes Wt Loss Ther. 2013:3(2):1-5.

18. Sorrie MB, Yesuf ME, GebreMichael TG. Overweight/obesity and associated factors among preschool children in Gondar City, Northwest Ethiopia: a cross-sectional study. PLoS One. 2017;12(8):e0182511.

19. TG G. Prevalence and associated factors of overweight and/or obesity among primary school children in bole Sub-City, Addis Ababa, Ethiopia. Nutrition \& Food Sciences. 2015;

20. Wolde T, Belachew T. Prevalence and determinant factors of overweight and obesity among preschool children living in Hawassa City, South Ethiopia. Prevalence. 2014:29

21. Tadesse Y, Derso T, Alene KA, Wassie MM. Prevalence and factors associated with overweight and obesity among private kindergarten school children in Bahirdar town, Northwest Ethiopia: cross-sectional study. BMC Res Notes. 2017;10(1):22.

22. Gebremichael B, Chere A. Prevalence of childhood overweight and obesity and its determinant factors among elementary school children in Addis Ababa, Ethiopia: a cross sectional study. J Nutr Disorders Ther S. 2015;1: 2161-0509.

23. Alemu E, Atnafu A, Yitayal M, Yimam K. Prevalence of overweight and/or obesity and associated factors among high school adolescents in Arada sub city, Addis Ababa, Ethiopia. J Nutr Food Sci. 2014;4(2):1.

24. Anteneh ZA, Gedefaw M, Tekletsadek KN, Tsegaye M, Alemu D. Risk factors of overweight and obesity among high school students in Bahir Dar City, north West Ethiopia: school based cross-sectional study. Adv Prev Med 2015. 2015 
25. Yetubie M, Haidar J, Kassa H, Fallon F. Socioeconomic and demographic factors affecting body mass index of adolescents students aged 10-19 in Ambo (a rural town) in Ethiopia. Int J Biomed Sci : IJBS. 2010;6(4):321.

26. Wakayo T, Whiting SJ, Belachew T. Vitamin D deficiency is associated with overweight and/or obesity among schoolchildren in Central Ethiopia: a cross-sectional study. Nutrients. 2016;8(4):190.

27. Teshome T, Singh P, Moges D. Prevalence and associated factors of overweight and obesity among high school adolescents in urban communities of Hawassa, southern Ethiopia. Current Research in Nutrition and Food Science Journal. 2013;1(1):23-36.

28. Teji K, Dessie Y, Assebe T, Abdo M. Anaemia and nutritional status of adolescent girls in Babile District, Eastern Ethiopia. Pan Afr Med J. 2016;24(1)

29. Robel Da. Assessment of sleep duration and overweight/obesity among high school adolescents in Addis Ababa, Ethiopia. In: Unpublished; 2016

30. Mulugeta S, Mekitie W, Alemayehu A, Sshikur M, Zewdu S, Mukerem A, Gebresillasea G. Magnitude and determinants of overweight and obesity among adolescent students at Addis Ababa. International Journal of Medical and Health Sciences. 2016;10(4)

31. Liberati A, Altman DG, Tetzlaff J, Mulrow C, Gøtzsche PC, loannidis JP, Clarke M, Devereaux PJ, Kleijnen J, Moher D. The PRISMA statement for reporting systematic reviews and meta-analyses of studies that evaluate health care interventions: explanation and elaboration. PLoS Med. 2009;6(7):e1000100.

32. Modesti PA, Reboldi G, Cappuccio FP, Agyemang C, Remuzzi G, Rapi S, Perruolo E, Parati G. Panethnic differences in blood pressure in Europe: a systematic review and meta-analysis. PLoS One. 2016;11(1):e0147601.

33. Rücker G, Schwarzer G, Carpenter J, Schumacher M. Undue reliance on 12 in assessing heterogeneity may mislead. BMC Med Res Methodol. 2008;8(79)

34. Higgins J, Thompson S. Quantifying heterogeneity in a metaanalysis. Stat Med. 2002;21:1539-58.

35. Sterne J, Egger M. Funnel plots for detecting bias in meta-analysis guidelines on choice of axis. J Clin Epidemiol. 2001;54:1046-55.

36. Egger M, Smith GD, Schneider M, Minder C. Bias in meta-analysis detected by a simple, graphical test. BMJ Open. 1997;315:629-34.

37. Fryar CD, Carroll MD, Ogden C. Prevalence of Overweight and Obesity Among Children and Adolescents Aged 2-19 Years: United States, 1963-1965 Through 2013-2014. Health E-Stats. 2016;

38. Cheung PC, Cunningham SA, Narayan KV, Kramer MR. Childhood obesity incidence in the United States: a systematic review. Childhood Obesity. 2016;12(1):1-11

39. Jahns L, Adair L, Mroz T, Popkin BM. The declining prevalence of overweight among Russian children: income, diet, and physical activity behavior changes. Econ Hum Biol. 2012;10(2):139-46.

40. Nakano T, Sei M, Ewis AA, Munakata H, Onishi C, Nakahori Y. Tracking overweight and obesity in Japanese children; a six years longitudinal study. J Med Investig. 2010;57(1, 2):114-23.

41. Raja'a YA, Mohanna MAB. Overweight and obesity among schoolchildren in Sana'a City, Yemen. Ann Nutr Metab. 2005;49(5):342-5.

42. Adegoke S, Olowu W, Adeodu O, Elusiyan J, Dedeke I. Prevalence of overweight and obesity among children in Ile-ife, South-Western Nigeria. West Afr J Med. 2009;28(4):216-21.

43. Senbanjo I, Adejuyigbe E. Prevalence of overweight and obesity in Nigerian preschool children. Nutr Health. 2007;18(4):391-9.

44. Ejike CE. Child and adolescent obesity in Nigeria: a narrative review of prevalence data from three decades (1983-2013). Journal of Obesity and Metabolic Research. 2014;1(3):171.

45. Yusuf S, Mijinyawa M, Musa B, Gezawa I, Uloko A. Overweight and obesity among adolescents in Kano Nigeria. J Metab Syndr. 2013;2:126.

46. Pienaar AE. Prevalence of overweight and obesity among primary school children in a developing country: NW-CHILD longitudinal data of 6-9-yr-old children in South Africa. BMC obesity. 2015;2(1):2.

47. Talat MA, El Shahat E. Prevalence of overweight and obesity among preparatory school adolescents in urban Sharkia governorate, Egypt. Egyptian Pediatric Association Gazette. 2016;64(1):20-5.

48. Belahsen R, Mziwira M, Fertat F. Anthropometry of women of childbearing age in Morocco: body composition and prevalence of overweight and obesity. Public Health Nutr. 2004;7(4):523-30.

49. Abrha S, Shiferaw S, Ahmed KY. Overweight and obesity and its sociodemographic correlates among urban Ethiopian women: evidence from the 2011 EDHS. BMC Public Health. 2016;16:636.
50. Hassen K, Gizaw G, Belachew T. Dual burden of malnutrition among adolescents of smallholder coffee farming households of Jimma zone, Southwest Ethiopia. Food Nutr Bull. 2017;38(2):196-208.

51. Moges B, Amare B, Fantahun B, Kassu A. High prevalence of overweight, obesity, and hypertension with increased risk to cardiovascular disorders among adults in Northwest Ethiopia: a cross sectional study. BMC Cardiovasc Disord. 2014;14:155

52. Tadewos A, Egeno T, Amsalu A. Risk factors of metabolic syndrome among hypertensive patients at Hawassa university comprehensive specialized hospital Southern Ethiopia. BMC Cardiovasc Disord. 2017;17(1):218.

53. Tebekaw $Y$, Teller C, Colon-Ramos U. The burden of underweight and overweight among women in Addis Ababa, Ethiopia. BMC Public Health. 2014;14:1126.

54. Worede A, Alemu S, Gelaw YA, Abebe M. The prevalence of impaired fasting glucose and undiagnosed diabetes mellitus and associated risk factors among adults living in a rural Koladiba town, Northwest Ethiopia. BMC Res Notes. 2017;10(1):251.

55. Gebremedhin S. Prevalence and differentials of overweight and obesity in preschool children in sub-Saharan Africa. BMJ Open. 2015;5(12):e009005.

56. De Onis M, Blössner M, Borghi E. Global prevalence and trends of overweight and obesity among preschool children. Am J Clin Nutr. 2010;92(5):1257-64.

57. Wang Y, Lim H. The global childhood obesity epidemic and the association between socio-economic status and childhood obesity. In: Taylor \& Francis. 2012;

58. Peltzer K, Pengpid S. Overweight and obesity and associated factors among school-aged adolescents in Ghana and Uganda. Int J Environ Res Public Health. 2011:8(10):3859-70.

59. Baalwa J, Byarugaba B, Kabagambe E, Otim A. Prevalence of overweight and obesity in young adults in Uganda. Afr Health Sci. 2010;10(4)

60. Tremblay M, Katzmarzyk P, Willms J. Temporal trends in overweight and obesity in Canada, 1981-1996. International journal of obesity and related metabolic disorders: journal of the International Association for the Study of Obesity. 2002;26(4):538-43.

61. Krassas G, Tzotzas T, Tsametis C, Konstantinidis TPrevalence and trends in overweight and obesity among children and adolescents in Thessaloniki, Greece. Journal of pediatric endocrinology \& metabolism: JPEM 2001, 14:1319-1326; discussion 1365.

62. Vignolo M, Pistorio A, Torrisi C, Parodi A, Grassi S, Aicardi G. Overweight and obesity in a group of Italian children and adolescents: prevalence estimates using different reference standards. Ital J Pediatr. 2004;30:53-7.

63. Wisniewski AB, Chernausek SD. Gender in childhood obesity: family environment, hormones and genes. Gend Med. 2009;6:76-85.

64. Kruger $\mathrm{R}$, Kruger $\mathrm{H}$, Macintyre $\mathrm{U}$. The determinants of overweight and obesity among 10-to 15-year-old schoolchildren in the north West Province, South Africa-the THUSA BANA (transition and health during urbanisation of south Africans; BANA, children) study. Public Health Nutr. 2006;9(3):351-8.

65. Dupuy M, Godeau E, Vignes C, Ahluwalia N. Socio-demographic and lifestyle factors associated with overweight in a representative sample of 11-15 year olds in France: results from the WHO-collaborative health behaviour in school-aged children (HBSC) cross-sectional study. BMC Public Health. 2011;11(1):442.

66. Daboné C, Delisle HF, Receveur O. Poor nutritional status of schoolchildren in urban and peri-urban areas of Ouagadougou (Burkina Faso). Nutr J. 2011;10(1):34

67. Freedman DS, Dietz WH, Srinivasan SR, Berenson GS. The relation of overweight to cardiovascular risk factors among children and adolescents: the Bogalusa heart study. Pediatrics. 1999;103(6):1175-82.

68. Monteiro CA, Moura EC, Conde WL, Popkin BM. Socioeconomic status and obesity in adult populations of developing countries: a review. Bull World Health Organ. 2004;82(12):940-6.

69. RCEd M, PICd L, Oliveira JS, Leal VS, SCdS S, SLLSd A. Prevalence and determinants of overweight in preschool children. J Pediatr. 2011;87(3):231-7.

70. Do LM, Tran TK, Eriksson B, Petzold M, Nguyen CT, Ascher H. Preschool overweight and obesity in urban and rural Vietnam: differences in prevalence and associated factors. Glob Health Action. 2015;8(1):28615.

71. Jagadesan S, Harish R, Miranda P, Unnikrishnan R, Anjana RM, Mohan V. Prevalence of overweight and obesity among school children and adolescents in Chennai. Indian Pediatr. 2014:51(7):544-9.

72. Badi MAH, Triana BEG, Martínez RS. Overweight/obesity and socioeconomic status in children from Aden governorate, Yemen, 2009. Revista Habanera de Ciencias Médicas. 2013;12(3):1-7. 
73. El-Hazmi MA, Warsy AS. A comparative study of prevalence of overweight and obesity in children in different provinces of Saudi Arabia. J Trop Pediatr. 2002;48(3):172-7.

74. Kyallo F, Makokha A, Mwangi AM. Overweight and obesity among public and private primary school children in Nairobi, Kenya. Health (N Y). 2013;5(08):85

75. Santos DA, Silva AM, Baptista F, Santos R, Gobbo LA, Mota J, Sardinha LB Are cardiorespiratory fitness and moderate-to-vigorous physical activity independently associated to overweight, obesity, and abdominal obesity in elderly? Am J Hum Biol. 2012;24(1):28-34.

76. Badawi NE-S, Barakat AA, El Sherbini SA, Fawzy HM. Prevalence of overweight and obesity in primary school children in port said city. Egyptian Pediatric Association Gazette. 2013;61(1):31-6.

77. Goyal RK, Shah VN, Saboo BD, Phatak SR, Shah NN, Gohel MC, Raval PB, Patel SS. Prevalence of overweight and obesity in Indian adolescent school going children: its relationship with socioeconomic status and associated lifestyle factors. J Assoc Physicians India. 2010;58:151-8.

78. Jain G, Bharadwaj S, Joglekar A: To study the prevalence of overweight and obesity among school children (13-17yrs) in relation to their socioeconomic status and Eating habits. Int J Sci Res Publ 2012, 2:1-4.

79. Börnhorst $C$, Wijnhoven TM, Kunešová M, Yngve A, Rito Al, Lissner L, Duleva V, Petrauskiene A, Breda J. WHO European childhood obesity surveillance initiative: associations between sleep duration, screen time and food consumption frequencies. BMC Public Health. 2015;15(1):442.

Ready to submit your research? Choose BMC and benefit from:

- fast, convenient online submission

- thorough peer review by experienced researchers in your field

- rapid publication on acceptance

- support for research data, including large and complex data types

- gold Open Access which fosters wider collaboration and increased citations

- maximum visibility for your research: over $100 \mathrm{M}$ website views per year

At BMC, research is always in progress.

Learn more biomedcentral.com/submissions 